\title{
5 Reasons to Include a Woman on Your Startup Team
}

\author{
Karen Brown (Bridge Arrow)
}

KEYWORDS: Entrepreneurship, Women, Diverse Entrepreneurial Teams.

Despite accounting for more than half of the US population, women are sorely underrepresented in the world of startups and entrepreneurship. A Harvard study notes that less than $40 \%$ of business owners and only $30 \%$ of high tech employees are women, and another

study(http://www.startupsusa.org/women-foundedventure-backed-startups/) in 2019 revealed that only about a fifth of American VC investment was going to startups with at least one woman founder.

The picture isn't pretty for women on the inside either: stories from the \#MeToo movement tell of rampant harassment at all kinds of businesses and a toxic "bro culture" in Silicon Valley, where only $17 \%$ of startups (https://www.citylab.com/equity/2019/02/women-startup s-venture-capital-investment-data-gender-gap/583132/) have a woman as a member of their founding team.

It's true that established companies and newer ones have been scurrying to adopt diversity programs to add more women and minorities and attempt to change their policies and their culture. But most of these programs are focusing on the wrong things. A 2014 Harvard Business Review article pointed out that today's diversity programs were largely spurred by sex discrimination lawsuits. And a PwC report found that for $77 \%$ of North American companies, the two biggest goals for their diversity and inclusion initiatives were complying with legal requirements and attracting and retaining employees; only $21 \%$ reported their main goal was achieving business results.

What's overlooked here is that including women on leadership teams will pay off in the results that matter most to business and particularly to startups: innovating, making money, avoiding costly mistakes and ensuring long-term survival.

From our own work and from hard numbers generated by research into this topic (https://bridgearrow.com/resources/running-circles-

around-the-ol-boys-clubs), we know that women give companies, both new and established, competitive advantages that translate into better performance. So here are five business reasons to include women on your startup team:

\section{Companies with women in leadership roles perform better}

Numerous studies over the past 15 years have correlated having women as leaders with stronger corporate financial performance. A 2017 McKinsey study found that US and UK companies in the top quartile of leadership team gender diversity had higher profit margins than their national industry median. And a Catalyst study of Fortune 500 firms between 2004-2008 found that companies with three or more women on their boards financially outperformed those with no women directors.

\section{Women encourage innovation}

A study by the Boston Consulting Group surveyed more than 1,700 companies worldwide and found that having women and other diverse people on the management team generated more revenue from innovation. And a 2010 study of nearly 700 people who worked in teams found that those with a greater percentage of women scored higher on measures of "collective intelligence," the ability to work together effectively on a diverse set of problem-solving tasks. The study's authors concluded that women scored higher than men on collective intelligence and were more likely to encourage all team members to contribute their knowledge and skills. This means that more potential innovative ideas have the chance to be heard.

\section{Women protect the firm's reputation}

A 2012 study by three Roger Williams University professors found that companies whose boards have a higher percentage of women directors were more likely to be included on "most ethical company" lists. A study of nearly 1,900 environmental lawsuits in the US from 
2000 to 2015 found that having female corporate leaders made it less likely that firms fell afoul of environmental laws. Adding women to boards and the Csuite is especially important in the \#MeToo era, corporate investigator and former UK-based prosecutor Dan Nardello told the Financial Times recently.

\section{Women take more prudent risks}

A 2015 study by two universities found that gender diversity improved how a company identified acquisition targets, for several reasons. One is that diverse teams are better at assessing complex information because women and men filter and interpret their environment differently; the other is that women in general tend to be more risk-averse, and thus less likely to pursue high-risk deals. One company that I know of abandoned an acquisition after a team of junior women uncovered information that the target company had not yet disclosed. Moreover, taking prudent, well-informed risks helps a company grow responsibly and stave off bankruptcy. A Leeds University Business School study found that a company's likelihood of filing bankruptcy declined by $20 \%$ when it had at least one female director; those with more women directors did even better.

\section{Women will strengthen the pipeline of future managers}

To grow over the long-term, companies must have a robust pipeline of capable leaders that can execute key initiatives and navigate crises. According to consulting company Korn Ferry, labor shortages will cost the global economy $\$ 8.5$ trillion by 2030 , equivalent to the combined GDP of Germany and Japan. Research from the National Association of Corporate Directors links talent with strategy and risk. More than $1 / 3$ of both public-company and provide-company directors list key talent deficits as a top five trend affecting their companies over the next 12 months, yet roughly half of directors express a low confidence in management's ability to respond to this trend. In fact, they've noted that competition for talent is identified as one of the major areas of risk alongside $M \& A$, crises, cybersecurity, ethics and compliance and culture. Yet women, who could increase the pool of future leaders, are still largely absent from top management in many critical sectors, including financial services, manufacturing and even fields like health care where they predominate in lowerlevel jobs.

Startups have the chance to build an effective team from the ground up. Seeking out qualified women and incorporating them into your startup team is not only the right thing to do, but also a sound business move. Matt Downs, co-CEO of Sandbox Industries, a venture capital firm that invests in agriculture and healthcare startups, puts it best:

"If you say, 'I need an African American in the room,' or 'I need a woman in the room,' you're missing it. I need a brilliant thinker with a different background than mine, who brings a different perspective, who will help us make effective decisions. And if you're established on that philosophy, then you're going to move in the right direction."

\section{References}

Running Circles Around the Ol Boys Club: The Unsung Advantages of Gender-Diverse Leadership Teams (https://bridgearrow.com/resources/running-circlesaround-the-ol-boys-clubs)

\section{Read More:}

Advice, Best Practices and Inspiration for Women Entrepreneurs(https://eiexchange.com/women)

Additional search terms: women, feminism, female founders, women business owners, glass ceiling, antidiscrimination, opportunity 